\title{
Sindicalismo e trabalhadores em cooperativas no Oeste do Paraná (décadas de 1990 e 2000)
}

\author{
Rinaldo José Varussa
}

\begin{abstract}
Resumo: Este artigo busca apresentar e discutir alguns elementos referentes às dinâmicas de atuação de sindicatos de trabalhadores em cooperativas no oeste do Paraná. Partindo do processo de constituição desses sindicatos e das formas de atuação identificadas, que parecem se articular à composição da categoria, delineio algumas ações empreendidas pelos trabalhadores na contraposição a essas entidades.
\end{abstract}

Palavras-chave: Sindicalismo; Cooperativas agropecuárias e trabalhadores; Condições de trabalho em frigoríficos.

Abstract: This article seeks to present and discuss some elements related to the dynamics of trade unions activities in Cooperatives of West Paraná. Starting the process of constitution of this union and forms of actions identified, which seem to articulate to the composition of the class, I outline some actions taken by workers in contrast to that entity.

Keywords: Unions; Agricultural cooperatives and works; Working conditions in slaughterhouses

Nas últimas décadas, foram frequentes as análises sobre o sindicalismo brasileiro que caracterizaram o final dos anos 1980 e os anos 1990 como um período de crise das organizações dos trabalhadores ${ }^{1}$. Essas análises, não raro, identificavam a crise a partir de dois elementos.

O primeiro, antes como um parâmetro, se fundamentava na expressiva mobilização dos anos anteriores, muitas vezes apontados como do surgimento de um suposto "novo sindicalismo", além de um conjunto de outros movimentos sociais, igualmente adjetivados com a novidade, a partir dos quais se articularam trabalhadores de diversos categoriais profissionais, notadamente, na contraposição às práticas da ditadura militar ${ }^{2}$. Em confrontação àquele período, a década de 1990 representaria uma expressiva redução da característica identificada nas duas décadas precedentes.

\footnotetext{
* Professor associado na Universidade Estadual do Oeste do Paraná (UNIOESTE), atuando nos cursos de graduação e mestrado em História; vinculado ao Laboratório de Pesquisa "Trabalho e Movimentos Sociais". Email: angri46@gmail.com.

${ }^{1}$ Entre inúmeros trabalhos, ver um balanço geral dessa discussão em ALVES, Giovanni. Trabalho e sindicalismo no Brasil dos anos 2000, dilemas da era neoliberal. In: ANTUNES, Ricardo (org.). Riqueza e miséria do trabalho no Brasil. São Paulo: Boitempo, 2006. Para uma contraposição às interpretações que identificaram uma crise no sindicalismo, ver BEYNON, Huw. O sindicalismo tem futuro no século XXI?. In: SANTANA, Marco Aurélio e RAMALHO, José Ricardo (orgs.). Além da fábrica: trabalhadores, sindicatos e a nova questão social. São Paulo: Boitempo, 2003.

${ }^{2}$ Sobre essa abordagem, cito o paradigmático SADER, Eder. Quando novos personagens entraram em cena. Rio de Janeiro: Paz e Terra, 1986. Para uma problematização da novidade do sindicalismo no período, ver MATTOS, Marcelo Badaró. Novos e velhos sindicalismos, Rio de Janeiro: Vício de Leitura, 1998.
} 
O segundo elemento, quase causa do primeiro, buscou fundamentar aquela crise como resultante de "tempos neoliberais", das mudanças ditadas pelos defensores de um "mundo globalizado", promotores de aberturas comerciais, do esgotamento do "modelo fordista" de produção - que, ainda que advindos com certo atraso ao Brasil, em comparação com países "centrais", acarretaram efeitos semelhantes, notadamente a fragilização do emprego formal, aprofundando "precarizações". Além de exigir mudanças nas formas de ações - haja vista a queda expressiva no número de greves -, aquele quadro empurrava as organizações dos trabalhadores para uma pauta defensiva, reconhecida, por exemplo, pela defesa de postos de trabalho e de garantias presentes na legislação trabalhista, ambos os pontos ameaçados por um conjunto de reformas que o empresariado buscava firmar no ambiente da produção. "Dessindicalização" e "reestruturação produtiva" tornaram-se as "palavras de ordem" dos intérpretes do período.

Embora o tom dos parágrafos acima possa sugerir, não é pretensão deste artigo se contrapor àquela importante produção, mas sim apontar que, para um modelo de sindicalismo implantado justamente a partir daquele período, a situação atribuída para parte expressiva do movimento sindical brasileiro parece não se aplicar. A não ser que se vislumbrem outros princípios, encontrados não entre pesquisadores do sindicalismo, mas nos manuais de autoajuda ou na percepção que parte da classe dominante tem das crises como momentos de se estabelecer oportunidades que levem a lucros ainda maiores. Afinal, para essa classe, "catástrofes são transformadas em lucrativas oportunidades para o redesenvolvimento e a renovação; a desintegração trabalha como força mobilizadora e, portanto, integradora." 4

O caso em questão refere-se a um conjunto de sindicatos que passaram a ter a representação de trabalhadores em cooperativas agropecuárias e de crédito, iniciada em 1992, a partir da primeira unidade que se tem registro, implantada na cidade de Guarapuava, no sudeste do estado do Paraná. ${ }^{5}$ Uma série de outras se estabeleceram, inicialmente, naquele estado: em 1993, o SINTRASCOOPA, em Palotina (com subsedes em Marechal Cândido Rondon e Assis Chateaubriand, registrado no Ministério do Trabalho e Emprego em 1997); em 1995, o SINTRACOOSUL, em Carambeí (com subsedes em Curitiba, Castro, Paranaguá e Guarapuava, registrado no MET em 1997); o SINTRASCOOP, em Cascavel (com subsede em Cafelândia e registro no MTE de 1993); em 1996, o SINTRASCOOM, em Medianeira (registro no MTE em 1997); e o SITRASCOOP-Sudoeste do Paraná, em Dois Vizinhos (com subsede em São João e registro no MTE de 1997). ${ }^{6}$

Essa organização se ampliou com a fundação, em 2005, da Federação dos

\footnotetext{
${ }^{3}$ Igualmente vasta é a produção bibliográfica sobre esse tema. Fico num exemplo pontual, pela diversidade de situações analisadas: ANTUNES, Ricardo (org.). Riqueza e miséria do trabalho no Brasil. São Paulo: Boitempo, 2006.

${ }^{4}$ BERMAN, Marshall. Tudo que é sólido se desmancha no ar. São Paulo: Cia. das Letras, 1993, p. 109.

${ }^{5}$ Em 2012, atuava na cidade de Guarapuava uma subsede do Sindicato dos Trabalhadores em Cooperativas da Região Sul do Paraná (SINTRACOOSUL).

${ }^{6}$ Os anos de obtenção do registro no MTE foram obtidos a partir da Convenção Coletiva de Trabalho (CCT) 2006-2008, p. 1, celebrada entre os sindicatos dos trabalhadores e a Federação e Organização das Cooperativas do Estado do Paraná (FECOOPAR; registrada no MTE em 2005), assinada em 7 de agosto de 2006.
} 
Trabalhadores Celetistas em Cooperativa (FETRACOOP), constituída a partir daqueles sindicatos paranaenses, e com a formação da Federação Nacional (FENATRACOOP), fundada em 7 de maio de 2006, em Brasília ${ }^{7}$, a qual obteve seu registro sindical no Ministério do Trabalho e do Emprego (MTE) em 2009.

Uma decorrência imediata da implantação dessa rede sindical foi a divisão das bases de sindicatos anteriormente estabelecidos, principalmente os de trabalhadores nas indústrias alimentícias e estabelecimentos bancários, tendo em conta os setores produtivos a que se vinculam as cooperativas. Assim ocorreu em todo o oeste e sudoeste do Paraná, onde os sindicatos daquelas categorias existiam previamente aos sindicatos do setor cooperativista: no setor da alimentação, os sindicatos de Francisco Beltrão (fundado em 1988), Medianeira (1990), Marechal Cândido Rondon (1989), Toledo (1986), Cascavel (1986) e Dois Vizinhos (1986); na atividade dos bancários, os sindicatos de Cascavel (1980), Toledo (1986), Sudoeste do Paraná (abarcando Francisco Beltrão e Dois Vizinhos, fundado em 1984) e Foz de Iguaçu (1981).

Em termos legais, a divisão da base tornava-se possível tendo em conta que, "para fins de enquadramento sindical das categorias econômica e profissional, há que se considerar a atividade preponderante do empregador (art. 511, § 2ㅇ, da CLT)". ${ }^{8}$ Tal enquadramento, porém, não evitou um conjunto de contestações por parte de entidades sindicais, em diferentes partes do Brasil onde a rede de sindicatos buscou se estabelecer, sendo a mais expressiva delas um conjunto de 27 pedidos de impugnação do registro sindical da FENATRACOOP, feitos ao MTE por diversas entidades sindicais, conforme evidenciado na portaria que registrou a federação. ${ }^{9}$ Tal portaria reconhecia a FENATRACOOP "com área de abrangência nacional", conferindo-lhe poder "para coordenação, representação e integração dos sindicatos dos trabalhadores das cooperativas brasileiras, tendo como representação o somatório das categorias e bases territoriais dos sindicatos a ela filiados" ${ }^{10}$, as quais, a despeito da jurisdição nacional que o MTE conferia, resumiam-se, como indicado na portaria, aos sindicatos do estado do Paraná. A Confederação Nacional dos Trabalhadores do Ramo Financeiro (CONTRAF) interpôs uma das impugnações acima, manifestando estranhamento, através de seu diretor Miguel Pereira, uma vez que o registro

contradiz entendimento anterior do MTE, explicitado em Nota Técnica, de que as cooperativas são sociedades de pessoas, e não de capital, o que impossibilita a constituição de sindicatos, e de que a representação dos trabalhadores deve ser

\footnotetext{
${ }^{7}$ Estatuto Social da FENATRACOOP, p. 1.

${ }^{8}$ In: TRT-PR-30282-2010-003-09-00-0-ACO-18420-2012, de 27 de abril de 2012. Disponível no site do TRT da 9a Região, <www.trt9.jus.br/internet_base/jurisprudenciaman.do?evento=Editar\&chPlc=4846418>. No caso dos bancários, além daquele princípio, a Justiça do Trabalho entende que "as cooperativas de crédito não são consideradas entidades bancárias, porquanto se tratam de sociedades de pessoas, sem fins lucrativos, com objetivos específicos previstos no estatuto e regidas pela Lei no 5.764 /71." Assim, "enquanto as instituições financeiras visam à obtenção de lucro, as cooperativas de crédito atuam no âmbito do interesse comum dos seus afiliados, com a finalidade precípua de promover a cooperação entre eles." In: TRT-PR-30282-2010-00309-00-0-ACO-18420-2012 - 6A. TURMA, publicado no DEJT em 27-04-2012. Disponível no mesmo site indicado acima.

${ }^{9}$ Diário Oficial da União, 7 de abril de 2009, seção I, p. 77.

${ }^{10}$ Ibidem.
} 
estabelecida de acordo com a natureza da atividade. ${ }^{11}$

Conjuntamente, a CONTRAF detalhava o mecanismo utilizado pela nova entidade para configurar sua base:

No dia 14 de maio, foram convocadas para a cidade de São Paulo 15 assembleias, todas no mesmo dia e local e somente com horários diferentes, para a criação de 13 entidades sindicais de trabalhadores e duas patronais. Alertadas pelos editais de convocação, representantes da CUT-SP, federações e sindicatos de trabalhadores dos diversos ramos envolvidos compareceram ao local das assembleias, acompanhados de representantes da DRT, e comprovaram a armação, inclusive a ausência de trabalhadores nas assembleias. ${ }^{12}$

Sobre esta forma de realizar assembleias, o diretor Miguel Pereira acrescentava:

Identificamos grau de parentesco entre os fundadores das diversas entidades, o que evidencia o conluio para a constituição desses sindicatos. Precisamos agir rápido para impedir que os trabalhadores em cooperativas sejam prejudicados. Não se trata de questionar a livre manifestação dos trabalhadores em definir a entidade sindical que deve representá-los, mas os métodos, práticas e intenções que estas novas entidades estão sendo criadas, a começar por serem iniciativas dos patrões. $^{13}$

As denúncias da CONTRAF acerca da formatação das assembleias da nova entidade sindical pareciam ser corroboradas pela inexistência de entidades sindicais - neste caso, Federações -, em três estados, critério presente na legislação trabalhista (art. 535 da CLT) para a constituição de Confederações. A situação perdurou até 2011, portanto, após a obtenção do registro sindical pela FENATRACOOP, como se evidencia nas convenções coletivas celebradas pela entidade em diversos estados, onde constava unicamente essa entidade como representante dos trabalhadores ${ }^{14}$.

A falta de federações estaduais não impedia a atuação da FENATRACOOP, como se observa em denúncia reproduzida pelo Sindicato dos Bancários de Dourados e Região, dando conta de um "desmembramento do sindicato interestadual MT/MS, e criação de sindicato Estadual (MS)". Para tanto, a entidade havia convocado uma assembleia em Caarapó (MS), em 15 de janeiro de 2011, na qual compareceram representantes dos sindicatos dos bancários de Dourados, Campo Grande e Naviraí, além da CUT estadual e do Sindicato dos Vigilantes de Dourados; constataram que

não havia nenhum trabalhador em cooperativas de crédito do Estado, os poucos trabalhadores que lá compareceram eram de uma cooperativa (agrícola) de Caarapó e, pelas informações colhidas, tinham recebido ordens de seus superiores

11 In: Cooperativas: Contraf convoca reunião para discutir "sindicatos fantasmas". Disponível em: <http://www.fetecsp. org.br/index2.php?option=com_content\&do_pdf=1\&id=43548>.

12 Ibidem.

13 Ibidem.

${ }^{14}$ As convenções coletivas celebradas pela FENATRACOOP em 25 de fevereiro de 2012 estão disponíveis em: <www.fenatracoop. com.br/site/?page_id=37467>. 
para comparecerem a uma reunião, do sindicato. ${ }^{15}$

Além de sindicatos interestaduais, a organização adotava o expediente da formação de sindicatos estaduais, como no caso do Sindicato dos Empregados em Cooperativas de Crédito do Rio Grande do Sul (SECOC), formado em 2009, com contestações da Federação e dos sindicatos dos bancários daquele estado.

Esses embates perduraram pelo menos até 2012, quando no 140 Congresso Estadual dos Trabalhadores em Cooperativas do Paraná, organizado pela FETRACOOP em 29 de abril, os presentes aprovaram um voto de repúdio às declarações da secretária de Relações de Trabalho do MTE, Zilmara David de Alencar. O repúdio tornaria a secretária "inimiga declarada da organização dos trabalhadores em cooperativas". Segundo os dirigentes sindicais presentes no Congresso, durante seminário sobre liberdade sindical organizado pelo Tribunal Superior do Trabalho (TST), no dia 26 de abril, em Brasília, a secretária teria atingido "a categoria ao afirmar que a categoria não existe e que os trabalhadores em cooperativas atrapalham a organização sindical no Brasil” ${ }^{16}$. Essa suposta manifestação da funcionária do $\mathrm{MTE}^{17}$, que tinha como uma de suas atribuições a emissão de registros sindicais, chama a atenção, uma vez que a abtenção do registro da FENATRACOOP dera-se durante a sua gestão, iniciada em 2007, em substituição a Luiz Antonio Medeiros. Soma-se a isso o fato de que, quando ainda exercia a função de coordenadora geral de registro sindical, ela fora a responsável pela emissão da certificação do registro sindical de ao menos uma das entidades que compõem a rede, o SINDCOOP$\mathrm{MG}^{18}$.

No mesmo Congresso da FETRACOOP, seu presidente (e também presidente do SINTRASCOOP), Clair Spanhol, produziu a seguinte contraposição à fala da funcionária do MTE:

A categoria, formada por mais de 500 mil trabalhadores no Brasil, não pode ser tratada como fantasma, pois temos em todas as esferas judiciárias do Brasil nosso reconhecimento como categoria e isso não pode ser ignorado pisoteado por uma pessoa desqualificada para oferecer tal julgamento. ${ }^{19}$

Ou seja, tal manifestação, que converteu as denúncias de um "sindicato fantasma" em "categoria fantasma", ao menos numericamente, fortalecia a defesa - 500 mil

\footnotetext{
${ }^{15}$ In: JORNAL BANCÁRIO - Informativo do Sindicato dos Bancários de Dourados e Região - MS, janeiro/fevereiro de 2012, ano XV, n.217, p. 3.

${ }^{16}$ Mais de 4.500 trabalhadores no 140 Congresso Estadual dos Trabalhadores em Cooperativas do Paraná. Disponível em <www.sintrascoopa.com.br/?p=6489>. Acesso em 30 de abril de 2012.

${ }^{17}$ Não foi evidenciada em outra fonte que não a notícia da entidade sindical sobre a manifestação da secretária Zilmara David de Alencar. A secretária teria participado do seminário sobre liberdade sindical no painel “Organização sindical: registro sindical, pluralidade e unicidade sindical, fontes de custeio". A palestra pode ser assistida na integra em <www.youtube.com/watch?v=aks5XclR3oM>. Acesso em 01 de maio de 2012.

${ }^{18}$ Ministério do Trabalho e Emprego/Secretaria de Relações de Trabalho/Coordenadoria-Geral de Registro Sindical, Certidão referente ao processo 46000-010796/99-03, 14 de setembro de 2006.

${ }^{19}$ Mais de 4.500 trabalhadores no 14․ Congresso Estadual dos Trabalhadores em Cooperativas do Paraná, op cit.
} 
trabalhadores por certo são bem mais visíveis e expressivos que duas dezenas de sindicatos e igual número de dirigentes - e conjuntamente, parecia expressar o ponto central em relação ao qual a disputa se fazia: a representatividade da rede de entidades formada no âmbito das cooperativas.

Mas se a legalidade dos sindicatos de trabalhadores em cooperativas e suas federações era garantida pelo registro obtido no MTE e nas sentenças obtidas na diferentes instâncias da Justiça do Trabalho (JT), caberia questionar a legitimidade de tais organizações sindicais em relação à categoria, da qual se nomeavam representantes - até porque o próprio dirigente restringiu o reconhecimento às "esferas judiciais".

A questão da representatividade, para além do enquadramento legal e do reconhecimento pelo MTE, se apresenta, no caso brasileiro, como um tema significativo e com desenvolvimento nas discussões implementadas pelos pesquisadores. E num primeiro aspecto em relação à esta produção, o $\mathrm{O}$ caso dos sindicatos tratados aqui parece acrescentar um encaminhamento ao que parte da bibliografia conceituou como "investidura sindical" (BOITO JR, 1991), a qual identifica no reconhecimento oficial de um sindicato "um monopólio da representação" que outorga ao representante legal poderes e direitos de efetivar, por exemplo, acordos em nome dos trabalhadores, independentemente de sua efetiva anuência. $\mathrm{O}$ acréscimo, como registrado acima e em principio, se daria à medida que os sindicatos dos trabalhadores em cooperativas firmam-se numa divisão de outras bases sindicais, tais como as dos bancários e dos alimentícios, reconfigurando a "unicidade sindical" advinda das "normas jurídicas [as quais] são a fonte da representatividade e [que] regulam, de maneira minuciosa, a sua organização interna e a sua atividade". Aparentemente, estes sindicatos reverteram uma parte da lógica vislumbrada por Boito Júnior: buscaram nos limites da legislação a garantia do direito de representar uma parcela dos trabalhadores. ${ }^{20}$ Tal garantia não retiraria, em princípio, aquele sindicato de uma ambiguidade apontada por diversas pesquisas e presente também na formulação de Boito Júnior: ao prescreverem a regulamentação que supostamente amarra a instituição sindical ao Estado, conquistariam sua autonomia nessa forma de representação, por conta do poder, assinalado acima, de efetivar acordos sem a participação direta dos representados. Percebese isso quando as discussões sobre a representatividade sindical, por vezes, buscam estabelecer maneiras como os trabalhadores devem se vincular aos sindicatos.

Uma das formas, se não a principal, de se pautar essa ligação dá-se através dos índices de sindicalização. Assim, a diminuição desses, a denominada "dessindicalização", seria vista como um aspecto da crise do sindicalismo ou, como conceitua Leôncio Martins Rodrigues, o "declínio sindical". 21

Em relação a esse índice, mesmo autores que apontam sua limitação reconhecem sua importância, como Alberto Moreira Cardoso, que identifica a não necessidade da filiação para que os trabalhadores usufruam das conquistas obtidas pelos sindicatos - ao que se

\footnotetext{
${ }^{20}$ BOITO JÚNIOR, Armando. O Sindicalismo de Estado no Brasil. Campinas/São Paulo: Edunicamp/Hucitec, 1991, p. 53.

${ }^{21}$ RODRIGUES, Leôncio Martins. O Declínio do sindicalismo. São Paulo: Edusp, 1999.
} 
apegam algumas sentenças da JT para legalizar descontos em folha de pagamento, como apontarei adiante - e pela força destes advir da sua capacidade de mobilização coletiva, o que independe do número de filiados ${ }^{22}$; nas dinâmicas de enfrentamento do "sindicalismo corporativo" pelo "novo sindicalismo", o autor aponta a importância para este último do aumento no número de sindicalizados, visando, ao menos, as disputas eleitorais ${ }^{23}$.

A consideração do índice de sindicalização para os sindicatos dos trabalhadores em cooperativas revela-se, porém, complexo, dado o mecanismo adotado por essas organizações para efetuar a cobrança das taxas sindicais. Assim, se tomados os descontos realizados em folha de pagamento, o "sindicalismo cooperativista" teria aparentemente revertido o "declínio sindical": seu índice de recolhimento de mensalidades, ao menos no que se refere às unidades do estado do Paraná, se aproxima de $100 \%$, portanto, bem acima da média nacional, que era de $17,7 \%$, segundo dados da Pesquisa Nacional por Amostra de Domicílios (PNAD) de 2009, do IBGE, e mesmo se comparado a sindicatos que supostamente se pautam pela busca de filiações nas suas bases, como aqueles vinculados à Central Única dos Trabalhadores (CUT), cujo índice, em 2009, era de 33,9\% ${ }^{24}$. Na CUT, um dos maiores índices de filiação era o do Sindicato dos Metalúrgicos de Taubaté e Região, com 85,8\% de filiações ${ }^{25}$.

O SINTRASCOOPA (de Palotina e região) também atingiu aquele índice de filiação das entidades "coirmãs" em 2011. No caso da subsede de Marechal Cândido Rondon, eram 3248 os "filiados" em março de 2012, segundo a secretaria da entidade, o que correspondia à quase totalidade dos empregados nas três cooperativas instaladas naquela cidade. Esse índice de "filiação", porém, era obtido através do que ficou estabelecido nos Acordos Coletivos de Trabalho (ACT), como, por exemplo, na cláusula 40 do biênio 2003-2004, repetida nos ACTs e CCTs dos anos seguintes: "será descontando mensamente na folha de pagamento do Trabalhador Cooperativista a percentagem de $2 \%$ (dois por cento) do valor do salário normativo da categoria a título de Contribuição Assistencial (...)"26

Ao que parece, os sindicatos tomavam essa "contribuição assistencial" como filiação, até porque não era evidenciada nos contracheques dos trabalhadores nenhuma outra forma de desconto ligada àquela entidade. Aos trabalhadores caberia a contestação do pagamento, conforme previsto no CCT 2006-2008:

Fica assegurado o direito de oposição a este instrumento, o qual deverá ser manifestado individualmente pelo empregado, diretamente nas dependências dos sindicatos laborais cooperativistas filiados à FETRACOOP em requerimento manuscrito até 10 dias da homologação do presente instrumento coletivo. ${ }^{27}$

\footnotetext{
${ }^{22}$ CARDOSO, Adalberto Moreira. A Década neoliberal. São Paulo: Boitempo, 2003, p. 208-209.

${ }^{23}$ Ibidem, p. 211.

${ }^{24}$ Cai o número de centrais sindicais reconhecidas pelo governo. 26 de maio de 2012. Disponível em: <www.vermelho.org.br/noticia.php?id_secao=8\&id_noticia=184278>. Acesso em 29 de maio de 2012.

25 Índice de sindicalização está entre os maiores do Brasil. Disponível em <www.cnmcut.org.br/verCont.asp?id=20831>. Acesso em 15 de dezembro de 2009.

${ }^{26}$ Ibidem.

${ }^{27}$ Convenção Coletiva de Trabalho 2006-2008, p. 16.
} 
Os CCTs e ACTs não previam o procedimento a ser adotado caso o trabalhador não se manifestasse fora do prazo de 10 dias, o que, no conjunto - necessidade da manifestação por escrito, pessoalmente e nas dependências do sindicato - sugere uma dificuldade maior para a "desfiliação" da entidade do que para a vinculação a ela, uma vez que esta era automática e imediata à contratação pelas cooperativas. Essa dificuldade dos trabalhadores fica evidenciada nos diversos processos instaurados na Vara do Trabalho de Marechal Cândido Rondon, nos quais eram frequentemente contestados aqueles pagamentos. A mesma situação parecia se repetir na Vara do Trabalho de Assis Chateaubriand, em seu posto de Palotina, a se considerar o processo TRT 1018/2007, no qual a C-Vale Cooperativa Agroindustrial recorria da decisão estabelecida em primeira instância, que garantira, entre outros itens, ao reclamante (então recorrido) a devolução da taxa assistencial. Nesta ocasião e item, a A cooperativa recorrente teve sua demanda acatada, uma vez que o TRT da 9a Região reformava a primeira sentença, entendendo que:

Se não foi estabelecida a necessidade de autorização ou concordância do empregado para o desconto, a taxa é devida a todos os empregados da categoria profissional atendida pelo sindicato obreiro signatário [da CCT], inclusive os não filiados, uma vez que também são alcançados pelas vantagens fixadas nas normas coletivas. $^{28}$

Nas recorrentes ações judiciais, os trabalhadores aparentemente indicavam as desvantagens advindas dessa representação sindical. Vale registrar que tal forma de obtenção de custeio apresentava-se como "bandeira de luta" das entidades, considerando a inclusão da cobrança da "taxa associativa negocial" no Rol de Reivindicações da FENATRACOOP, firmado em 29 de abril de 2012, em Assembleia Geral Extraordinária realizada em Campo Mourão-PR, com mesma configuração exposta acima (ressalvando que haveria um teto de $\mathrm{R} \$ 20,00)$, aparecia como item da pauta para o "exercício 2012".

O desconto, há que se destacar, não era exclusividade dos sindicatos ligados às cooperativas na região: o mesmo expediente era adotado pelos sindicatos de trabalhadores das indústrias alimentícias, conforme se evidencia na CCT Carnes e Derivados do biênio 2010-2011, celebrada pela Federação dos Trabalhadores nas Indústrias Alimentícias do Estado do Paraná e assinada em 3 de maio de 2010. O mesmo ocorria em outras regiões do país, onde tal prática também é presenciada, como na CCT da Federação dos Trabalhadores nas Indústrias Alimentícias do Estado de São Paulo, assinada em 21 de julho de 2010 e que trazia aquele expediente em sua cláusula 46. Esses sindicatos e federações se respaldavam em decisão do Supremo Tribunal Federal (STF), que, em decisão de 7 de outubro de 2000 evidenciando que a contestação àquela prática era mais ampla que no caso do Oeste do Paraná -, estabelecera como "legítima a cobrança de contribuição assistencial imposta aos empregados indistintamente em favor do sindicato, prevista em convenção coletiva de trabalho, estando os não sindicalizados compelidos a satisfazer a mencionada

\footnotetext{
${ }^{28}$ Ibidem.
} 
contribuição."29 Por outro lado, não é possível afirmar a normalização do expediente, considerando as posições assumidas por outras instituições, como por exemplo, a ressalva presente na CCT dos alimentícios de São Paulo, citada acima, para os Sindicatos de Franca e Tupã, os quais abriam mão da contribuição.

No que se refere aos trabalhadores, não era apenas a via judicial de contestação da cobrança da taxa assistencial que relativizava a representatividade sindical. Nas entrevistas realizadas, o sentido estabelecido por eles para o sindicato aponta igualmente aquela situação, reforçando, se não a ilegalidade dos descontos e da representação, uma suposta ilegitimidade. Nesse sentido, um conjunto de 56 trabalhadores, entrevistados em diversas pesquisas $^{30}$ e empregados nas cooperativas da base do SINTRASCOOPA, principalmente nos frigoríficos daquelas empresas - 42 daquele total de entrevistados - permite interpretar duas avaliações recorrentes acerca da atuação das entidades sindicais.

Uma primeira forma de avaliação dos sindicatos cooperativistas remete aos "serviços prestados", como o faz Adinan Wenzel, 39 anos, casada, havia três anos no frigorífico de Marechal Cândido Rondon quando da entrevista, trabalhando como seladora (atribuição de embalar as carnes com filme PVC). Quando perguntada sobre a existência da entidade, a trabalhadora respondeu: "Tem, tem sim. É ali perto do Colégio [Estadual] Eron [Domingues]. Ah, é bom, né? O sindicato é bom, tem dentista, advogado. Eu levo as crianças lá e não pago nada!" ${ }^{31}$ Essa "clássica" presença do sindicato, caracterizada pela bibliografia como assistencial e que remete às dinâmicas constituídas após a década de 1930, de contenção das demandas dos trabalhadores e relacionadas à forma como a regulamentação dos sindicatos atrelara-os ao Estado, parece ser vista positivamente não apenas por Adinan. A se julgar pelo cartaz fixado na Agência do Trabalhador de Marechal Cândido Rondon ${ }^{32}$, a empresa também "via com bons olhos" estes serviços:

\footnotetext{
${ }^{29}$ Publicada no Diário Oficial da União, 10 de agosto de 2001.

30 Este artigo se beneficia de um trabalho coletivo que vem sendo realizado por diversos pesquisadores vinculados ao Laboratório de Pesquisa "Trabalho e Movimentos Sociais", bem como de trabalhos efetivados por colegas de outras áreas, como Enfermagem e da Geografia da UNIOESTE, os quais, nos últimos anos, investigam e discutem diferentes dinâmicas vividas e constituídas pelos trabalhadores da região oeste e sudoeste do Paraná, relativas a um processo de industrialização que acontece nas últimas décadas naquelas regiões.

${ }^{31}$ Entrevista com Adinan Wenzel, realizada por Ariele de Vargas, em 23 de março de 2010. Os nomes dos entrevistados foram substituídos.

${ }^{32}$ Este órgão público era responsável por mediar as contratações para o frigorífico na cidade.
} 


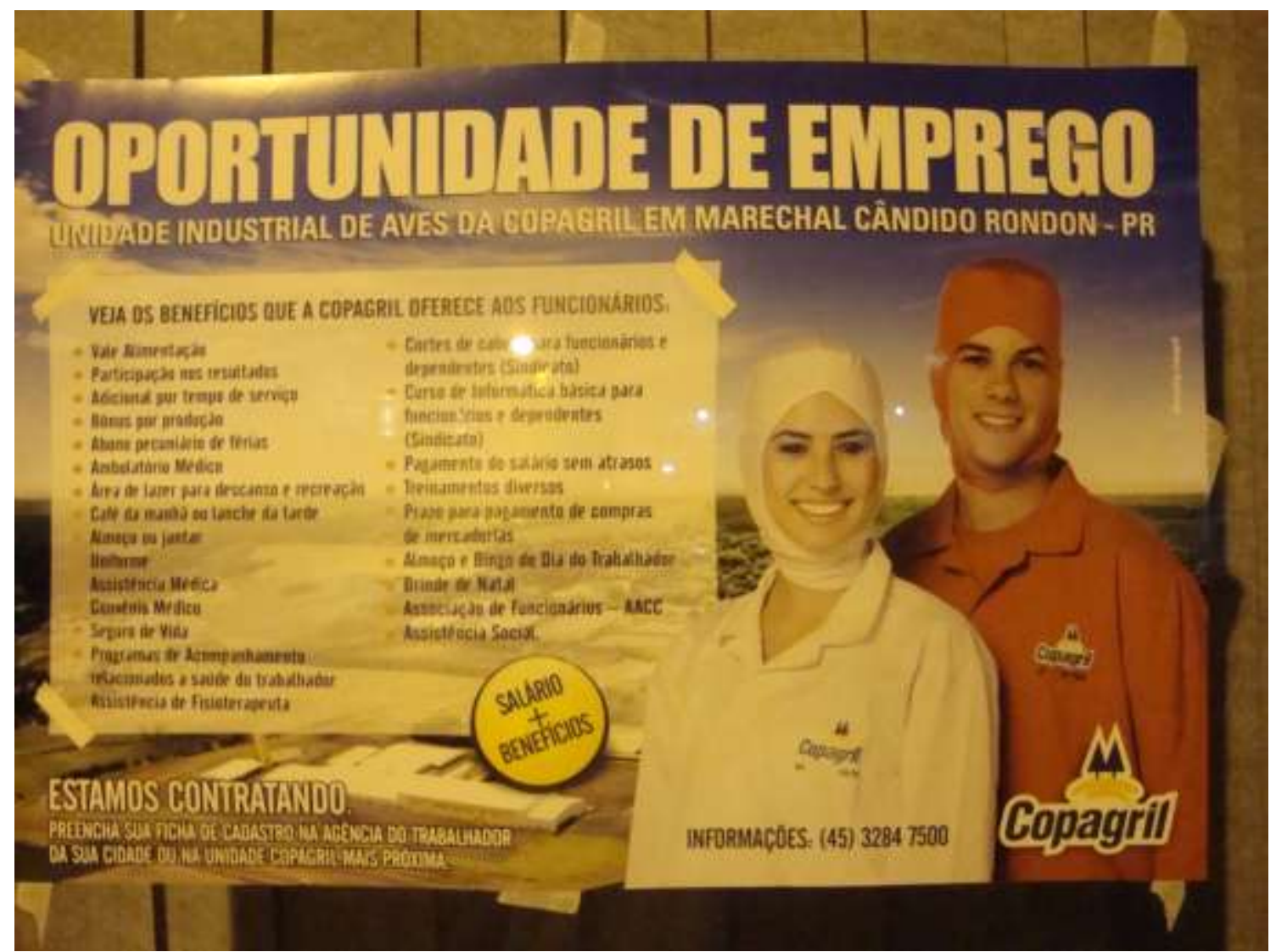

Foto: Rinaldo José Varussa (6 de maio de 2011).

Para além da forma sui generis como direitos - tais como o "pagamento do salário sem atrasos" - são transformados em "benefícios", e alguns serviços oferecidos - como a "assistência de fisioterapeuta", sugerindo um ato falho da empresa, dadas as condições de trabalho enfrentadas pelos futuros empregados -, chamam a atenção, na segunda coluna dos "benefícios", dois serviços prestados pelo sindicato: corte de cabelos e curso de informática.

O aparente alinhamento entre a empresa e o sindicato, que ficaria evidenciado também nos processos trabalhistas instaurados contra a empresa ${ }^{33}$ e no "subsídio" que os sindicatos cooperativistas recebiam das empresas, previstos na CCT citada acima, parece não passar despercebidos aos trabalhadores, mesmo quando se situam no "campo dos serviços prestados", como se depreende desta fala de uma trabalhadora:

O sindicato ... que tem ali é o SINTRASCOOPA, né? É o sindicato das cooperativas, né? [...] Isso [o desconto sindical] que eu não sei pra onde vai ... Que nem, o sindicato, se eu precisar de dentista, eu tenho que pagar uma taxa, se eu preciso ... a única coisa que eu sei que faz ali, não paga nada, é cortar cabelo e escovar, fazer unha. Tem que fazer no meio da semana, porque no sábado, a mulher sai onze

\footnotetext{
${ }^{33}$ Nas ações judiciais instauradas na Vara do Trabalho de Marechal Cândido Rondon, quando os trabalhadores contestaram a representação sindical do SINTRASCOOPA, os advogados patronais se contrapuseram, reiterando "a legitimidade do Sintrascoopa como representante da categoria específica, que são os empregados em cooperativa". In: VARA DO TRABALHO de Marechal Cândido Rondon, Processo n. 1347, 2007, folha 18.
} 
horas. Esses dias, nós tava falando: é nós pagar sindicato, aí, nós quer arrumar unha, tem que pagar caro pra arrumar unha, porque o horário que elas tão fazendo ali, é a hora que nós tamos trabalhando, sábado de manhã, nós temos nosso serviço pra fazer, em vez de eles abrir sábado à tarde, pra fazer unha e arrumar cabelo, eles não abrem, né? Então, nós pagamos e não desfrutamos. ${ }^{34}$

A fala da trabalhadora Ivone Machado, 50 anos, que trabalhava na linha de cortes do frigorífico rondonense havia dois anos quando da entrevista, além de firmar a dissociação do serviço prestado pelo sindicato às situações vividas pelos trabalhadores para justificar a inutilidade da taxa, afinal "nós pagamos e não desfrutamos", alude a uma desconfiança quanto à destinação da taxa sindical - "eu não sei pra onde vai" - conjuntamente à construção de um distanciamento da entidade, conceituada como "sindicato das cooperativas" e não dos trabalhadores, e à "clássica" distinção efetivada no uso dos pronomes "eles" (na fala da trabalhadora, "elas") para a entidade, e "nós", para os empregados.

Tal desconfiança se alia, por vezes, ao desconhecimento do sindicato, à maneira como o sindicato se apresenta, ou mais propriamente, se ausenta da relação com os trabalhadores, como fica evidente na fala de Arno Souza, 40 anos, que trabalhou na sala de cortes do frigorífico durante oito meses em 2008, quando pediu demissão para trabalhar em outra empresa. Perguntando sobre a existência do sindicato, o trabalhador produziu a seguinte interpretação:

É, na verdade tem [sindicato], sabe. Só que ninguém sabe pra que serve... Todo mundo sabe que tem o sindicato. Mas saber porque... De vez em quando, tem um aviso no mural lá, algo assim... Mas, tem gente que nem sabe onde é...[...] E outra: esse sindicato é que nem pai de santo: só recebe. Só aparece pra nós lá na folha aquele desconto todo mês ... Eu acho que eles deveriam pensar mais nos trabalhadores e menos neles, é isso que eu acho! ${ }^{35}$

A avaliação de Arno Souza, estabelecendo uma dissociação entre a direção do sindicato e os interesses dos trabalhadores - "eles" e "nós", novamente -, reforçada na presença percebida apenas nos descontos efetuados nos contracheques e que inaugura um "novo sindicalismo", o "pai de santo" - informava sua concepção de como seria conduzida a definição de um reajuste salarial:

O reajuste na verdade nem existe, é uma porcaria, não aumenta porcaria nenhuma! A firma coloca lá só cinco por cento. Daí, o sindicato pede dez. Aí, a firma diz: então, dou seis. Daí, o sindicato aceita! Que reajuste que é esse, seis por cento?![...] A gente trabalha um ano inteiro pra ganhar uns trocados de trinta ou quarenta reais... $^{36}$

\footnotetext{
${ }^{34}$ Entrevista com Ivone Machado, realizada pelo autor em 27 de fevereiro de 2011.

${ }^{35}$ Entrevista com Arno Souza, realizada por Ariele Souza de Vargas, em 12 de fevereiro de 2010.

${ }^{36}$ Ibidem.
} 
A insatisfação do trabalhador com o processo de negociação e o valor do salário parecia encontrar respaldo, ao menos, numa possível comparação com os valores recebidos pela categoria em outros lugares. Nesse sentido, destaca-se a diferença entre o piso salarial dos trabalhadores da base dos sindicatos das cooperativas e o obtido em outras regiões do país. Assim, os valores presentes no CCT 2006-2008, que definia o piso da categoria em R\$ $415,00^{37}$ - após um reajuste de $3 \%$ - apresentava uma defasagem de quase $25 \%$ em relação aos trabalhadores de frigoríficos do estado de São Paulo ${ }^{38}$, por exemplo. Em alguns casos, a diferença se acentuava, como configurado no ACT celebrado entre Matadouro de Aves Flamboiã e o Sindicato dos Trabalhadores em Indústrias Alimentícias de Jundiaí e região, em 1 ㅇ de maio de 2007 , que definia um piso salarial de $\mathrm{R} \$ 625,38^{39}$, portanto, $50 \%$ superior aos valores do piso salarial rondonense para a categoria. ${ }^{40}$

A referência dos trabalhadores ao sindicato a partir dos serviços prestados e do reajuste de salário, por sua vez, expressa uma ausência na pauta do sindicato e na maneira de se relacionar com a categoria: as condições de trabalho que, nas últimas três décadas, pelo menos, vêm atentando contra a saúde dos trabalhadores, ocasionando um quadro epidêmico de lesões por esforços repetitivos (LER) e distúrbios osteomusculares relacionados ao trabalho (DORT), além de milhares de acidentes no espaço da produção, como apontam diversos pesquisadores ${ }^{41}$.

\footnotetext{
${ }^{37}$ Este CCT, assinado em 7 de agosto de 2006, estabelecia em sua cláusula 4.2, p. 2, três tipos de piso salarial para trabalhadores efetivados (que já haviam cumprido o período de experiência) e que atuassem em indústrias de carne: $R \$ 465,00$; $R \$ 425,00$ para os trabalhadores que recebessem vale refeição, ou vale alimentação, ou vale mercado, ou cesta básica; e, caso do frigorífico rondonense, R\$ 415,00 para os trabalhadores que recebessem algum daqueles vales acrescidos de prêmio de produtividade, não definido no CCT. O valor da cesta básica e dos vales não era especificado no CCT, mas ficava estabelecida a possibilidade de descontos desses em folha de pagamento (cláusula 9). No CCT 2008-2010, assinado em 2 de julho de 2008, curiosamente, não ficou estabelecido piso salarial, com o que se presume que não ocorrera alteração em relação ao contrato anterior, tendo em conta o valor de $R \$ 415,00$, tomado como parâmetro para o cálculo de insalubridade (cláusula 35.2).

${ }^{38}$ Para o ano de 2006, a Federação dos Trabalhadores nas Indústrias da Alimentação do Estado de São Paulo assinou com as indústrias frigoríficas, em 1 을 de maio, um CCT que definia salário normativo de $R \$ 518,59$, após uma correção de $6 \%$, para as empresas que complementassem aquele piso com uma cesta básica com valor mínimo definido de $R \$ 50,00$ (cláusula 5). Para as empresas que não concedessem cesta básica, o normativo seria de R\$543,68. In: OFíCIO CIRCULAR n.039/2005-DJ Referente Convenção Coletiva de Trabalho, p. 1. A fim de estender a comparação, vale citar que o salário mínimo nacional em 2006 era de $\mathrm{R} \$ 350,00$.

${ }^{39}$ Ao piso salarial, era acrescida uma cesta básica mensal - com os itens que a compunham especificados na cláusula 4 - destinada aos trabalhadores que não apresentassem falta injustificada.

${ }^{40}$ Conforme discuti em Industrialização, trabalhadores e Justiça do Trabalho no Oeste do Paraná (década de 1990): algumas considerações, a diferença salarial entre os valores recebidos pelos trabalhadores no Oeste do Paraná e regiões de produção industrial mais antiga, entre outros fatores, configurava-se como um elemento atrativo para o deslocamento de alguns setores produtivos, como o alimentício e, mais especificamente, o frigorífico de aves para aquela região. In: Tempo da Ciência. Cascavel, Edunioeste, 2006, p. 145-156.

${ }^{41}$ Para o estado do Paraná, Fernando Heck, em levantamento realizado nos dados da Previdência Social a partir das notificações a que estão obrigadas as empresas, constatou 12258 afastamentos nos frigoríficos paranaenses, no período de 2006 a 2010. Como chama a atenção Heck, esse índice representava aproximadamente $20 \%$ de trabalhadores da categoria atingidos no estado, dado que seriam perto de 60 mil trabalhadores no estado. In: HECK. Fernando. Para a crítica do desenvolvimento regional: o território da degradação do trabalho e seus impactos na saúde e vida dos trabalhadores, 2012 (mimeo). Especificamente para região oeste do Paraná, ver NELI, Marcos A. Reestruturação produtiva e saúde do trabalhador: um estudo com os trabalhadores de uma indústria avícola. Dissertação (Mestrado), Faculdade de Medicina, Universidade
} 
Para além da concentração da pauta nos temas acima, essa ausência fica evidenciada nos CCTs assinados pelo sindicato: até 2010 - ano do último contrato a que tive acesso -, as condições de trabalho, no que se referem especificamente à saúde do trabalhador, apareciam apenas de forma genérica, na cláusula 35, que trata da insalubridade e nos seguintes termos:

DO ADICIONAL DE INSALUBRIDADE E PERICULOSIDADE. Permanecendo as condições insalubres e perigosas, constatadas através do laudo L.T.C.A.T (Laudo Técnico das Condições Ambientais de Trabalho) e se a Cooperativa não vier a suprilas mediante o fornecimento de equipamentos de proteção individuais e/ou coletivos de proteção ao trabalho, pagará aos empregados submetidos a essas condições os respectivos adicionais de periculosidade e insalubridade previstos na legislação em vigor. $^{42}$

O mesmo tratamento sumário estava presente no Rol de Reivindicações para o exercício de 2012. Nesse documento, especificamente no ponto Itens de Segurança e Medicina do Trabalho, redigido a partir de 13 subtemas, nenhuma referência foi feita ao quadro enfrentando pelos trabalhadores dos frigoríficos. Aliás, em todo o documento, nem mesmo a palavra frigorífico aparece. Essa abordagem da questão, porém, não parecia se relacionar ao desconhecimento da situação, uma vez que nos processos trabalhistas, as manifestações do advogado do SINTRASCOOPA - outro serviço prestado pela entidade -, Márcio Berti, assumiam contornos dramáticos quanto ao ambiente de trabalho existente no frigorífico rondonense, que contribuiria para que em breve se formasse "no munícipio um exército de deficientes", caso a empresa "não mudar seu comportamento", uma vez que, embora "os trabalhadores [fossem] o alicerce para a alta rentabilidade da Cooperativa [...] em troca se acometem de doenças funcionais e aí são dispensados como uma pilha usada, estando inaptos para o mercado de trabalho." ${ }^{43}$

A omissão do sindicato contrastava com o sentido que parecia ser atribuído pelos trabalhadores ao problema. De maneira geral, as condições de trabalho se apresentam como um dos determinantes na constituição de uma característica da categoria firmada, ao menos na última década. Como apontado em outro estudo, no caso do frigorífico de Marechal Cândido Rondon, entre 2008 e 2010, a média anual de troca de empregados teria sido superior a $100 \% .{ }^{44}$ Para ficar-se na base do SINTRASCOOPA, ainda que em menor proporção (aproximadamente a metade) da verificada em Marechal Cândido Rondon, no frigorífico de Palotina, a situação de rodízio também era acentuada, conforme a tabela abaixo:

de São Paulo, Ribeirão Preto, 2006; CÊA, George S. S. e MUROFUSE, Neusa T. Associação dos portadores de LER (AP-LER) na luta pelos direitos dos trabalhadores de frigorífico do oeste do Paraná. In: TUMOLE, P. S. e BATISTA, R. L. Trabalho, economia e educação: perspectivas do capitalismo global. Maringá, Praxis, 2008.

${ }^{42}$ Convenção Coletiva de Trabalho 2008-2010, folha 16.

${ }^{43}$ In: Processo n. 973/2007, instaurado na Vara do Trabalho de Marechal Cândido Rondon.

${ }^{44}$ Ver a respeito VARUSSA, R. J. Trabalhadores e frigoríficos na Justiça do Trabalho: Oeste do Paraná, décadas de 1990 e 2000 (mimeo). 
Tabela I: Demissões e admissões em frigoríficos de aves - Palotina-PR (C.Vale)

\begin{tabular}{|l|c|c|c|c|c|c|}
\hline Ocupação & $\mathbf{2 0 0 5}$ & $\mathbf{2 0 0 6}$ & $\mathbf{2 0 0 7}$ & $\mathbf{2 0 0 8}$ & $\mathbf{2 0 0 9}$ & $\mathbf{2 0 1 0}$ \\
\hline Margarefe & & & & & & \\
\hline Admissões & 2061 & 1140 & 1749 & 2056 & 1451 & 1118 \\
\hline Demissões & 1209 & 1252 & 1268 & 1945 & 1178 & 1381 \\
\hline Sem justa causa & 862 & 800 & 122 & 141 & 172 & 177 \\
\hline A pedido do trabalhador & 304 & 360 & 511 & 797 & 507 & 688 \\
\hline Saldo & 802 & -112 & -481 & 273 & 273 & -263 \\
\hline
\end{tabular}

Fonte: CAGED/MET. Org. por Rinaldo José Varussa.

Considerando que trabalham no abatedouro de Palotina cerca de 3,5 mil trabalhadores, o índice médio dos seis anos apontados na tabela I estaria próximo a $40 \%$ para as demissões e superior a $45 \%$ para as admissões, caracterizando uma troca de trabalhadores, já que ambos os índices se aproximam. Em relação a isso, o elemento marcante na possível troca é a preponderância da decisão dos trabalhadores (a pedido destes) na constituição da situação, nos últimos quatro anos da tabela: nesses, as demissões solicitadas pelos empregados foram superiores a quatro vezes as demissões "sem justa causa", as quais, necessariamente, não tenham decorrido também da iniciativa dos trabalhadores, tendo em vista outros expedientes que informam essa caracterização. Porcentagem semelhante de demissões "a pedido do trabalhador" observa-se também no frigorífico rondonense.

Se da parte empresarial, o fenômeno era compensado pela busca de trabalhadores cada vez mais longe da sede industrial - aproximadamente $60 \%$ dos trabalhadores do frigorífico rondonense eram oriundos de 14 municípios em $2010^{45}$-, da parte dos trabalhadores, o que se observa é a constituição de uma rejeição pelo trabalho naquele setor. $^{46}$

No que se refere à rede de organização sindical tratada aqui, o êxodo dos trabalhadores e o curto tempo de vinculação à categoria, aliados aos mecanismos de financiamento da entidade constituído nos CCTs - que garante às entidades sindicais descontos automáticos na quase totalidade da categoria - parecem pactuar favoravelmente na manutenção da sua forma de atuação.

Nesse sentido, um aspecto denotado entre os trabalhadores foi a ausência de registro em suas memórias de disputas pela direção da entidade, no caso do SINTRASCOOPA, e mesmo a participação deles em processos eleitorais, o que não significa que não tenham acontecido. Contrastando com a instabilidade da categoria, o que se pode afirmar neste item é a estabilidade alcançada pelos quadros dirigentes, haja vista sua permanência desde a constituição da entidade nas cidades de Palotina e Marechal Cândido

\footnotetext{
${ }^{45}$ GEMELLI, Diane D. Mobilidade territorial do trabalho como expressão da formação do trabalhador para o capital: frigorífico de aves da Copagril de Marechal Cândido Rondon/PR, Francisco Beltrão. Dissertação (Mestrado), Universidade Estadual do Oeste do Paraná. Programa de Pós-Graduação em Geografia, 2010.

${ }^{46}$ Uma sistematização mais detida deste aspecto pode ser vista em BOSI, Antonio. A Cultura da Classe: a recusa do trabalho em frigoríficos no Oeste Paranaense (1990-2010) (mimeo).
} 
Rondon. As entidades, assim, teriam garantida a manutenção das suas operações, independentemente da "volatilidade" da categoria, sendo necessária apenas a manutenção do número de empregados-contribuintes.

Tendo presente esses elementos, que caracterizam tal sindicalismo, é pertinente concluir com Marshal Bermann: “Um século depois [de Marx], podemos ver como o negócio de promover revoluções está sujeito aos mesmos abusos e tentações, às mesmas fraudes manipuladoras e ilusões embromadoras de uma campanha promocional qualquer" ${ }^{47}$

Recebido em 10/05/2012

Aceito para publicação em 15/06/2012

${ }^{47}$ BERMANN, op cit., p. 130. 